\title{
Fostering Commonfare. Infrastructuring Autonomous Social Collaboration
}

\author{
Peter Lyle, Mariacristina Sciannamblo, Maurizio Teli \\ Madeira Interactive Technologies Institute \\ Funchal, Portugal \\ \{peter.lyle, cristina.sciannamblo, maurizio.teli\}@m-iti.org
}

\begin{abstract}
Recently, HCI scholars have started questioning the relationship between computing and political economy, with both general analyses of such relationships, and specific design cases describing design interventions. This paper contributes to this stream of reflections, and argues that IT designers and HCI scholars can critically engage with the contemporary phase of capitalism by infrastructuring the emergence of new institutional forms of autonomous social collaboration through IT projects. More specifically, we discuss strategies and tactics that are available for IT designers embracing an activist agenda while infrastructuring autonomous social collaborations. We draw on empirical data from an H2020 EU funded project - Commonfare - that seeks to foster the emergence of alternative forms of welfare provision rooted in social collaboration. In this context, we discuss how the necessary multiple relations that unfold in a project with such ambitions shape both the language and the technologies of the project itself.
\end{abstract}

\section{ACM Classification Keywords}

K.4.0. Computers and Society: General; K.4.2. Computers and Society: Social Issues; H.5.m. Information Interfaces and Presentation (e.g. HCI): Miscellaneous

\section{Author Keywords}

Strategies and tactics; infrastructuring; participatory design; political economy; welfare; configuring participation; social collaboration.

\section{INTRODUCTION}

Digital technologies are now part of the everyday experience of a growing number of people, and they relate to economic, social, and political life, from dating sites to political participation, from new global labour markets to maintaining contact with the loved ones. In the light of this, a growing number of HCI scholars are questioning the socio-economic role of technology. This inspection remains faithful to conceiving

This work is licensed under a Creative Commons Attribution International 4.0 License.

CHI 2018 April 21-26, 2018, Montreal, QC, Canada

(c) 2018 Copyright held by the owner/author(s)

ACM ISBN 978-1-4503-5620-6/18/04

DOI: $10.1145 / 3173574.3174026$ digital technologies as socio-technical systems that require an understanding not only of the technical components, but also of their social, political, and economic implications.

This paper is in a dialogue with such stream of research and it takes a complementary angle, reflecting on the transformation of the European welfare state and describing a design process that fits into such transformations with a progressive agenda. The reasons for technology designers to engage in a progressive agenda are rooted in the risks of collapse of our current social arrangements (already highly unequal) toward darker scenarios, as highlighted by observers in the social sciences [22] and in social informatics [20]. This extends to the role digital technologies play in the social processes potentially bringing about these social, political, and environmental dark scenarios. The focus on the welfare state, instead, is based on a historical argument and a contemporary empirical fact. Historically, the establishment of the welfare state has been the main way through which wealth has been redistributed, and its "golden age" has been described as the only period in recent history in which social inequalities have been reducing [35]. Empirically, the neoliberal reduction of welfare states in Western Europe (and in Eastern Europe after the collapse of the Soviet Bloc) has been sided by a growth in economic inequalities and harshness on people's lives [21]. In fact, official statistics report that now, in the European Union, almost $24 \%$ of the population is at risk of poverty or social exclusion, accounting for more than 120 million people, and $8 \%$ of the population is experiencing forms of severe material deprivation where, for example, people are unable to eat enough proteins over a week or to cope with unexpected expenses of relatively small amounts. Even after social transfers by the state, such as minimum income support schemes, housing or family allowances, $17.3 \%$ of the population is at risk of poverty [17]. The combination of the growing relevance of digital technologies in economic life, the historical retrenchment of the welfare state, and the actual conditions of the European population suggests that there is a design space for HCI and Participatory Design researchers in dealing with contemporary welfare states.

It is within this context that we introduce and describe the Commonfare project, an large scale participatory design research undertaking, funded by the Horizion 2020 Framework Programme of the European Union (EU). The Commonfare project seeks to respond to the changing European welfare 
state through the design and development of socio-technical systems with an aim to foster solidarity among those at risk of social exclusion and poverty across multiple countries within the EU. Commonfare draws upon the welfare model to focus on two main aspects: supporting autonomous social collaboration and experimenting with self-organised digital currency. Approximately the first year of design and development activities as part of the Commonfare project serve as our case, as we apply the theoretical lens of strategies and tactics, articulated by de Certeau [9] in the context of infrastructuring studies (e.g. $[4,29]$ ), to understand the different plans and actions that have been taken. We refer to infrastructuring, and not just infrastructure, in line with previous work focusing not on "being" of infrastructure, but to the more ecological viewpoint of "becoming" an infrastructure [44].

The contribution to the HCI community is therefore to illustrate how participatory design can be used within a large scale infrastructuring project, by bringing together infrastructure studies and political economy. For the HCI community, this understanding, and the conceptual tools we use to build our case, serve as an example of how designers and researchers can engage in a deeper reflection on the rationale that underpins technology design, in terms of who is participating, and how their participation is configured. In particular, we contribute to an understanding of the relationship between strategies and tactics in terms of establishing and negotiating project boundaries respectively. We therefore pose our research question as the following: How can HCI scholars and designers understand the configuration of participation in a large scale infrastructuring project rooted in political economy?

The paper is organised such that we first unpack political economy in the context of $\mathrm{HCI}$ research, before introducing concepts of strategies and tactics as analytical tools to interpret the process of infrastructuring and participatory design. With these concepts established, we then introduce the case study of Commonfare and our approach - an examination of a biography of project artefacts that detail the first year of the project. We then look at specific aspects of this chronological sequence of events and discuss, specifically, the use and development of the language used to talk about the project and the social relations at play. Finally, we conclude by re-connecting the described strategic and tactical actions to the question of how scholars and designers can engage in large scale infrastructuring projects while seriously considering political economy.

\section{HCI AND POLITICAL ECONOMY}

The HCI community has, only recently, started to question the relation between $\mathrm{HCI}$ itself, digital technologies, and the political economy of contemporary digital capitalism, with a few seminal works focusing on specific projects $[24,11]$ or general views of computing and capitalism [16]. As a first notable case, Lilly Irani and Six Silberman [24] have discussed the case of the Turkopticon browser add-ons, capable of supporting workers' interactions and employers accountability on Amazon Mechanical Turk. A few years later, Dombrowski et al. [11] discussed how HCI research and practice could support workers to identify wage theft and then engage in collective action through relevant NGOs. The relation between the individual and their social relations also appear as key in the work by Snow and colleagues [42, 41], who show how design projects engaging low income populations should have as a central element the support and construction of social relations. In all cases, the reference to political economy is mediated: in Irani and Silberman, through a description of activist technologies; in Dombrowski et al. by the relationship between HCI and work studies; in Snow and colleagues through the focus on "low income" as a defining trait of the involved population.

A different perspective is the one proposed by Hamid Ekbia and Bonnie Nardi who, in different papers $[13,14,15]$ and a book [16], have focused on the political economy of computing. Their attention is given to the transformation of labour toward what they refer to as heteronomation, pointing to the subordinating of human activities to the (algo)rhythms of the machines. According to them, heteronomation came to be as a result of structural transformations in capitalism following the crises in the 1970s. In this renewed context, the success of contemporary technologies could be interpreted as a search for "possibilities [of] (...) economic prosperity, universal education, political participation, self-expression, and shared ideas and projects" [16, p. 81] while the structure of contemporary capitalism make people face four main predicaments: a sense of separation from social ties like friends, families, or neighborhoods; job precarity, with the end of the model of one-job-for-life; the social pressure to futile consumption; and a widespread monotony requiring growing stimuli. In their analysis, Ekbia and Nardi are aligned with the concerns for the viability of the current model of capitalism with many critical thinkers, in fields like social informatics [20], sociology [18], or media studies [38, 43].

It is interesting that, when proposing their "real utopias" (drawing upon the sociologist Wright [48]), Ekbia and Nardi suggest "A basic guaranteed income is in the program, as well as a state that safeguards basic rights, including education and healthcare" [16, pp. 189-190]. In fact, a similar suggestion has been advanced by other scholars in economics (only partially known to Ekbia and Nardi) that have been proposing an update of the welfare state to the current stage of capitalism through the concept of "commonfare". Commonfare, as a novel model for welfare distribution of wealth, is indeed based on the three points raised by Ekbia and Nardi, a guaranteed income, access to education and healthcare, to which it adds free access to knowledge and the management of shared resources as commons (for the concept of commons, see Ostrom [33]). In fact, Ekbia and Nardi points to commons-based practices, like making, but they do not connect it to commons as alternative institutions, something argued for by scholars in social informatics [20], in HCI [46], and by the economists proposing "commonfare" as an alternative form of welfare provision [19]. Following this suggestion to contribute to the shaping of new institutions, we should stress how a focus on institutions goes hand-in-hand with the participatory design of digital technologies, in what has been called "institutioning" [23]. This challenges the narrative of corporations as agents of institutional change, such as Uber, changing the institutional 
settings of taxi services, or Facebook itself, that has recently updated its mission as an infrastructure for communities.

In light of the above, we argue that to consider designing digital technologies as a form of designing new institutions is crucial for those interested in bringing forward the quest for "real utopias" that Ekbia and Nardi are advancing (and they are not alone, see Hakken et al. [20]). Such utopias, in Ekbia and Nardi perspective, should favor autonomy of people instead of heteronomation, the subordination of people to machines. With ICT companies representing seven out of the ten richest companies in the second half of 2017, and the characteristics of contemporary platforms to regulate the collaboration of multiple people, any effort to engage in realising utopian alternative institutions should: engage with the ambition of being large scale, and infrastructure autonomous forms of social collaboration. In this paper, we take the point of view of the designers of digital technologies in a large scale project fostering commonfare as an alternative institutional form, and we address the question on how designers could engage in such ambitious infrastructuring projects.

\section{PARTICIPATORY DESIGN AND INFRASTRUCTURING}

As mentioned before, we foresee a possibility for HCI scholars and IT designers to engage in projects with large-scale ambitions in the domain of welfare state and political economy, with the goal of promoting autonomous social collaboration more than heteronomation. To keep up with this ambition, there is a need to connect the objective of such kind of projects, infrastructuring autonomous social collaboration, with the design approach used. Due to the engagement of participatory design scholarship with projects considering political economy, we consider participatory design as the first design approach to focus our attention. Therefore, in this section we articulate the existing connections between participatory design research and infrastructuring, referring to concepts of strategies and tactics as tools to understand the scale and scope of large information infrastructuring projects. Participatory design approaches, used within information infrastructuring projects are not new, although there is a lack of focus on the spatial scaling of this type of research [26]. Our work, therefore, serves to look beyond the scope of local communities and organisations, adding to the very few examples of participatory design applied to infrastructuring that attempt to address the element of scale, like in the case of government identification schemes [8].

When conducting design, we recognise the importance of understanding how the participation of different people and groups is configured, and that this configuration will impact the social collaboration that takes place [47]. The way in which infrastructuring projects configure participation relates in part to their understanding and definition of the 'installed base' $[30,32]$, recognising that information infrastructures are not created or developed in a vacuum, and that the configuration of participation is in itself a political act, requiring reflexivity on the side of the designer, especially when considering the scale of infrastructures [34].

In the case of organisational IT infrastructure change, infrastructuring can be modeled as a process of convergence of technology and work process design and development, towards a point of infrastructure, denoting these processes from primarily in development, to primarily in use [36]. The stage that follows, then, focuses on the tailoring and appropriation. This is presented as a single snapshot of an infrastructuring process, which may be appropriate in some workplace settings with clear organisational and project goals. In other situations such as a local organic food community [4] - the tailoring and appropriation decisions combined with different internal and external forces, ultimately leads towards a new understanding of the needs of the community, and so, to a new process of infrastructuring. As will be clarified later, while the Commonfare project shares some characteristics of an organisational IT infrastructure project in terms of goals and deadlines agreed upon as part of its funding, the use of participatory design presents a need to adapt and respond to participation of individuals and groups, and their situations. In the following, we refer to the tensions between more fixed elements like deadlines and more adaptive aspects as a tension between strategies and tactics.

\section{Strategies and Tactics}

We draw on the concepts of strategies and tactics [12], which Bødker et al. [4] introduce in the context of infrastructuring projects as a lens through which to understand the source and impact of decisions made by a social aggregate engaged in parallel infrastructuring activities.

The analytical capacity of the concepts of strategies and tactics comes from the work of de Certeau [9], who discusses them to distinguish between different types of decision and action. Strategies are "...actions which, thanks to the establishment of a place of power (the property of a proper), elaborate theoretical places (systems and totalizing discourses) capable of articulating an ensemble of physical places in which forces are distributed" [9, Ch. 3]. By contrast, tactics are positioned as "a calculated action determined by the absence of a proper locus. No delimitation of an exteriority, then, provides it with the condition necessary for autonomy. The space of a tactic is the space of the other." [9, Ch. 3]. De Certeau provides an example where language and speech serve as the strategic and tactical grounds on which spoken communication occurs. How language is defined and constructed is planned (as a strategy) and creates the space in which speech (as a tactic) can operate. Speech does not define the space, but has mobility and flexibility within language, not just to use the tools provided, but to change them in response to different needs. Strategies therefore are associated with planning, have power to define the space and the language by which we can engage in a system. Tactics, by contrast, lack this power and in doing so have an innate mobility, and reliance on opportunity. In other words, tactics are the domain of creative action, a crucial aspect of infrastructuring (e.g. [25]).

The work of Bødker et al. [4] applies these concepts of strategies and tactics within the context of a local community in Denmark, focusing on the ways in which different people act within the community over a period of years, and the different motivations and decisions that are made as a result of changing circumstances. Their analysis is based on a self-organised 
community, not bound by expectations from a funding body, and that allowed for an ad-hoc, flexible approach $[4,5,6]$, where the community members themselves conducted the infrastructuring work, developing tools for themselves. Regarding infrastructuring, it is indeed possible to go beyond the locally rooted and self-organised community to refer to dispersed populations interested in similar issues. This is what Le Dantec and Di Salvo in HCI have called "publics" [28, 10, 27]. With this term, they refer to groups of people who are dispersed, but have an interest in a specific issue, and the task of design is also the one of creating connections among the members of a public while infrastructuring in a participatory way. The reference to publics shows how the self-organised group described by Bødker et al. [4] could be one kind of social aggregates with which designers interact. This also raises the theme of what happens after design in terms of organisation and management, as discussed by Teli et al. [46], foreseeing the possibility for newly aggregated publics to manage digital commons, intended as specific institutional forms. The difference between Bødker et al. [4] and the "publics" lens points to different ways in which participation in the design and management of a digital artefact could be configured, and these differences are worth being exposed, as suggested by Vines et al. [47]. As we will describe through our case study, the Commonfare project, we foresee the strategies and tactics analytical framework as a promising one to understand a process of infrastructuring promoted by a variety of partnering organisations who are dealing with a dispersed population. Accordingly, the research question we address focuses on the configuration of participation within infrastructuring projects. Participation, in such a case, gets continuously reconfigured, with different points of infrastructure that become relevant points in understanding, over time, how strategic and tactical actions unfold in such an infrastructuring process.

\section{CASE STUDY AND METHOD}

Commonfare is a participatory design case aiming to tackle so-called societal challenges in the European Union such as precariousness, low income, poverty, and unemployment. The project is being carried out in three European pilot countries, targeting different populations: unemployed youth in Croatia, precarious workers in Italy, non-Western migrants, precarious workers and freelancers in The Netherlands. Research and design activities are conducted by a rather heterogeneous and interdisciplinary consortium composed of both academic and non-academic actors: two universities and an academic research center, three local NGOs, and two software development/research non-profits. These actors carry out different yet interrelated activities. The three local NGOs (pilot partners) are in charge of reaching out to the local population and establishing connections with local institutional bodies, arranging and reporting about design workshops, organising and participating to project-oriented events, conducting research about the welfare systems of their respective countries, and providing content for the platform. The universities and academic centers are based in different European countries and are responsible for the management and scientific coordination of the project, the coordination of public engagement activities, and the research on social engagement and dynamics systems to be implemented on the platform. Finally, the two software development/research partners work on the actual design of the platform, on the evaluation tasks related to the performance of the platform and the website, and on the construction of the digital currency model to be implemented on the platform. The goal of all these activities is to build up a digital platform with three essential purposes: (1) to provide information about welfare state provisions and policies in the three pilot countries; (2) to develop storytelling tools so that people and groups engaged in bottom-up welfare practices around Europe will be able to connect with each other; (3) supporting the most promising of these practices in order to let them scale up at the national and European level.

The project has been described as a "public design" project [7], in which the design and implementation of the digital platform at stake, commonfare.net, goes together with the strengthening of existing - and the construction of new - forms of autonomous social collaboration on the issues the project is focusing on. In line with the suggestions to build new institutions while designing, the project is also seeing commonfare.net as a "digital commons" [46], and the research and design work done is questioning both the technologies and the social, economic, and political aspects of commonfare.net as the digital result of the infrastructuring process, with a particular focus on the concept of commonfare as a novel welfare model based on autonomous social collaboration.

When dealing with strategies and tactics, the Commonfare project contrasts from the already discussed work by Bødker et al. [4] in terms of the structure of the population the project is dealing with - where we engage with a dispersed public, as opposed to a localised self-organised community -, the relationship of the researchers with the population - where we are directly engaged researchers as opposed to observers -, and who is building the digital technologies at stake - where we, as a consortium, engage with participants, as opposed to community members who build technology themselves. Moreover, Commonfare is a project funded by the European Commission (hence, EC), with an accepted project proposal turned into a grant agreement, which provides a grounding and starting point with which to shape the project work (while B $\varnothing \mathrm{dker}$ et al.'s [4] case is more deeply bottom-up).

In this paper, the Commonfare project constitutes a case study and we will present it as a biography of the infrastructuring process $[31,37]$. This narrative allows for a description of the project actions to be later on interpreted through the concepts presented above. In this section, we provide information useful to ground the biography of the project in the social and organisational contexts in which the infrastructuring process is unfolding. Given the complexity and the inevitable unexpected events that a similar project entails, the Biography of Artefacts (BoA) perspective [37] appears as a helpful way to describe and problematise the multiple relations at stake in the project. As Pollock and Williams explain, the BoA constitutes a lens that encompasses both the short-term dynamics surrounding the selection, implementation and embedding of new technologies as well as the longer-term evolution of practices and technologies (see table 1); such an approach, then, allows 
Table 1. List of Empirical Sources

\begin{tabular}{l}
\hline Internal Documents \\
\hline Design workshop reports \\
\hline Minutes of general assemblies \\
\hline Reports from focus group self-evaluation \\
\hline Design workshop plans \\
\hline Low and high fidelity mockups \\
\hline Emails within the consortium \\
\hline Internally developed glossary \\
\hline Public Documents \\
\hline Grant agreement \\
\hline Deliverables \\
\hline Info materials (factsheets, press releases, project \\
flyers) \\
\hline Advertisement for local events \\
\hline Commonfare.net \\
\hline
\end{tabular}

us to account for "both stability and change in sociotechnical relations and how these can be addressed over different time spans" [37, p. 530] with regard to the development of largescale information systems - such as commonfare.net - that are intended for long-term use with multiple users and uses.

For example, a similar perspective allows us to identify three different macro-actors in the project: the EC (as the funding agency), the consortium, and the participants (i.e. the potential users of the platform). While these actors are involved in the same process, they pursue their own agenda, work practices, and beliefs. For example, as the supervising institutional body, the EC oversees the agreed key deadlines of the platform releases and makes sure that the consortium produces the required documents. The consortium, by comparison, in its heterogeneity, is generally devoted to ensure a balance between the institutional deadlines and the genuine goal to pursue an effective participatory process. In this respect, participants' voices are key and, through the mediation of consortium's practices and decisions, they could have an impact on the institutional setting. As we present in the following sections, these actors elaborate tactical and strategic actions in order to handle the relations with each other as well as to manage tensions and concerns of design activities. In order to unfold our discussion, we draw upon a wide range of empirical sources that the consortium has produced in its first year of activity; these sources are divided into internal and public documents as showed in Table 1. This contrasts with the work of Lyle et al. [29], whose focus was on a smaller time period and of particular interactions between pilot and some academic partners.

\section{THE BIOGRAPHY OF COMMONFARE.NET}

Here we follow a BoA narrative across the timeline of Commonfare, from its inception to the design phase of the second release of commonfare.net, which corresponds approximately

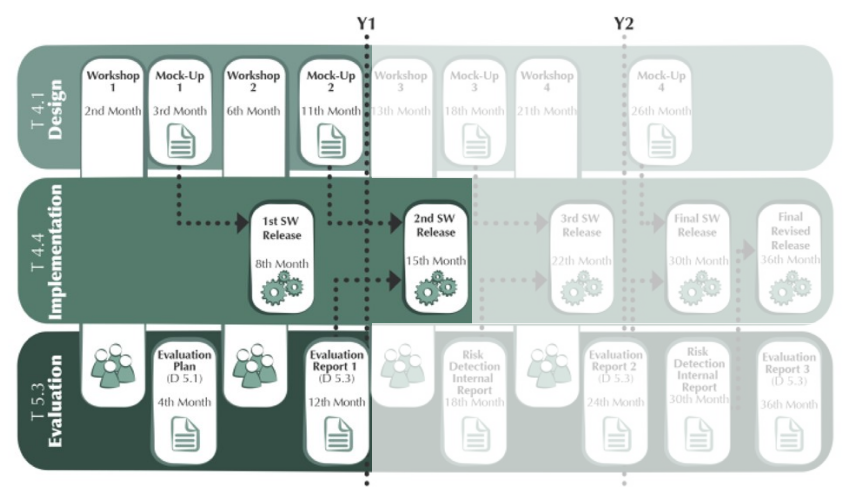

Figure 1. The time-line of the project according to the accepted project proposal.

with the first year of the project, as shown in Figure 1. The account is from the perspective of the consortium - specifically the author(s) - who have thematically analyzed the data sources listed in Table 1 in order to reconstruct the relevant points of infrastructure, and the relative strategic and tactical actions by the actors involved. The description follows Figures 2, 5 and 6, highlighting different strategic and tactical actions, as well as points of infrastructure, extending the visual representation used by Bødker et al. [4].

\section{One Year of Commonfare}

\section{Project Proposal and Grant Agreement}

The European Commission (hence EC) issued the call for proposal on "Collective Awareness Platforms for Sustainability and Social Innovation", oriented toward levering the collaborative capabilities of digital technologies to promote socially meaningful innovation [40], in the scope of the research Framework Programme Horizon2020 (hence H2020), thus setting up the space for the formation of new research projects and groups (Figure $2 ; 1$ ). The call was for what are called "Research and Innovation Actions", in which research should bring to tangible outcomes and, in this context, several actors from different European countries agreed to form a consortium to promote a project oriented to contrast socio-economic inequalities through the design of a collaborative digital platform (2). The consortium tactically acted within the space of the H2020 CFP to assemble a project proposal under the title 'PIE News', describing the population to be involved in the project using Eurostat (the statistical body of the EC) labels, e.g. at-risk-of-poverty-or-social-exclusion, and the language of the call for proposals, and submitted 'PIE News' to the EC in April 2015 (3). The title 'PIE News' referred to the development of a platform through which news, stories and experiences could be shared among people experiencing Poverty, lack of Income and unEmployment. With the description of 'PIE News', the project proposal already included a goal of "fostering commonfare" as an alternative model of welfare provision. The project proposal, that strategically used the concept of public design $[46,7]$ to describe the design process in order to open up the space for tactical appropriations of the design and implementation, has been approved in September 2015 (4). After the official approval, the EC defined the space 


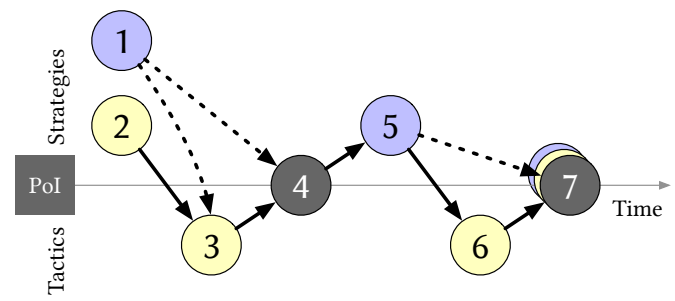

Figure 2. Strategies, Tactics of the EC (blue) and Commonfare Consortium (yellow), and Points of Infrastructure (grey) of the Project Proposal.

for the approved project, requiring additional work through the grant agreement, to accommodate changes in the EC policies on research ethics (5). The consortium tactically acted within these requirements, adjusting the project plan to accommodate the required extra work (6), and then consortium and EC signed the grant agreement (7).

\section{From Kickoff Meeting to Release 1 (R1)}

On July 2016 the kick-off meeting of the project took place (Figure 5; 8), with all the members of the consortium convening for the first time and discussing the general organisation of project activities as far as each issue (e.g. project management, communication, evaluation, pilot actions, data management) is concerned. Each macro-issue pertains to a different work package (hence WP), consisting of a group of related tasks assigned to a set of different partners, with a responsible WP leader. The project, as it is described in the grant agreement and presented during the kickoff meeting, consists of $6 \mathrm{WPs}$, one of which - WP6 on ethics - was added by the EC during the Grant Agreement Preparation phase to accommodate changes in EC policies, extending beyond the initial proposal by the Consortium. For each issue there was a set of actions to be undertaken and decided collectively by the consortium (9). During the kickoff meeting, the date of the first design workshop (DWS1) was also set up, with the consortium deciding it to be held in Zagreb, September 2016. During DWS1, pilot partners also shared with the consortium the plans of research activities to be conducted in the following months in the three countries in order to identify emerging needs and bottom-up welfare initiatives, so as to ultimately write the research report agreed upon in the grant (10).

Soon after the DWS1, pilot partners began working in each country in order to carry out the activities included in WP2 (11). These activities mostly concerned organising the empirical research with target populations in each country (12), to identify the specific needs of participants and local bottomup welfare practices. The result of these activities has been presented in the research report deliverable required by the EC and submitted under the agreed deadline (13). It should be noted how the results summarised in this report have been meant to be the basis for the design activities, as the report constitutes a detailed picture of the social conditions of the population the project is working with, through statistical and qualitative information. In fact, this report, "Deliverable 2.1" as it is called [3], had been based on official statistics and the involvement of approximately 250 people through interviews,

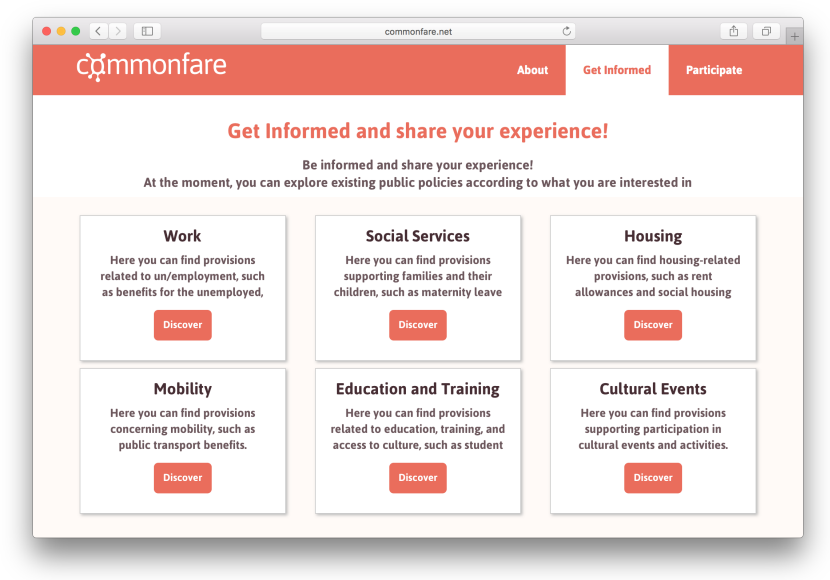

Figure 3. The main page of Commonfare.net Release 1, showing different categories of welfare provisions.

focus groups, or workshops. The description of the context touches many aspects, from the transformations of the labour market to personal debts, and is therefore a rich picture of the design space in terms of social context, with particular reference to the needs of the interested population and to good practices of bottom-up welfare (e.g. critical consumption and solidarity initiatives or organisations committed to civil society empowerment and immigrant integration). A similar work, taking into account the large empirical input into Deliverable 2.1 , with a more specific focus on components like reputation, digital currency, and social networking tools, was planned in relation to WP3, and the results have brought to the construction of personas and scenarios [1]. Both of these then, later on, became the basis for design requirements for commonfare.net. Both of these reports were planned as framing the design and implementation activities, on a more general or specific level.

In January 2017 the first general assembly (hence GA) and DWS2 took place jointly in Croatia as agreed during DSW1 (14). A key moment of the meeting has been the selfevaluation focus group conducted with pilot partners in order to discuss their experience with the empirical research and, more in general, about the project (15). During this focus group, many partners, as well as Croatian participants in a parallel focus group, expressed their dissatisfaction with the language used until then to describe the project, a vocabulary deeply marked by the bureaucratic rhetoric typical of institutional funding agencies like the EC. In particular, the preliminary results of the empirical work conducted in the pilot sites suggested that the participants where refusing the labels of "poor" or "socially excluded" employed by official statistics [39]. What emerged, indeed, is that the target populations can count on a wealth of social relations, therefore they refuse to feel themselves excluded, even if it is financially impossible for them to address unexpected expenses of a few hundred Euros [2]. The language issue emerging in the selfevaluation focus group touched other themes, always related to the original proposal language, like using the word "user" to refer to people or "stakeholder" to refer to organised entities. There have been two main consequences of such reflection on 


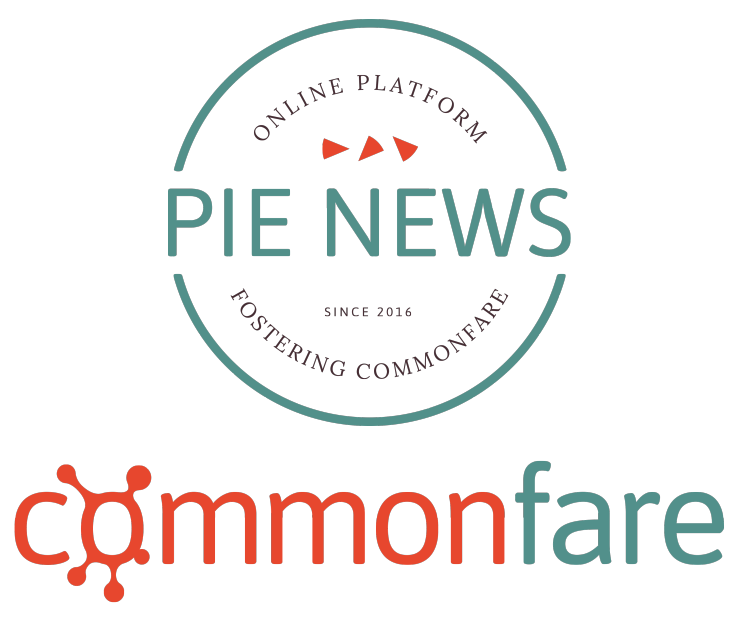

Figure 4. The old (top) and new (bottom) project logo.

language: the most significant decision was that of changing the language of the project, starting from its very name - from PIE News to Commonfare (17); then, the consortium elaborated a strategic plan in order to tackle the language issue by deciding to construct a common internal glossary (18). The resulting change (with regard to the logo) is shown in figure 4.

As to design activities, the design team started working on the development of low fidelity mockups based on feedback gained from Croatian participants at DWS2 (16). The "design team", roughly the part of the Consortium connected to WP4, continued working, incorporating feedback from the low fidelity mockups, which then became the basis for a high fidelity iteration (19). These high fidelity mockups, with additional feedback from the consortium, provided the basis for the development which resulted in the first release (20). Figure 3 shows the main page of the first release, and the six different welfare provision categories. It should be noted how the initial work by the consortium was pointing to four main categories and it was the empirical work, including the focus group with Croatian participants, that provided elements suggesting to increase the number of categories.

From Release 1 (R1) Toward Release 2 (R2)

Beginning in March 2016, the next phase of empirical work that took place was planned by the consortium members who had been heavily involved in the design of R1, the design team outlined a number of example workshop or interview questions to address two main goals: to elicit feedback from participants on the usability of R1; and to gain insight for R2, regarding whether the storytelling focus was valid and insight into participants' experiences with sharing stories using other technology (figure $6 ; 21$ ). Some of the preliminary results, already visible through Deliverable 2.1 [3], highlighted diverse approaches to storytelling, both connected to the cultural context (e.g. the Croatian population seemed more skeptical about telling complex stories and looked more interested in quick information on employers' behavior, while the Italian participants were way more positive) or to different interests, with organised groups more interested in self-promotion than individual participants. To further investigate such aspects, a

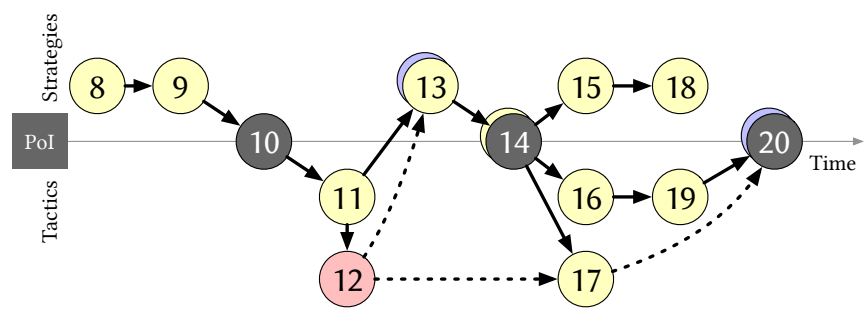

Figure 5. Strategies, Tactics of the EC (blue), Commonfare Consortium (yellow) and Participants (red); and Points of Infrastructure (grey) of the process from the Kick-off meeting to $R 1$.

field activities plan was then tailored to the individual contexts of each country during the course of multiple meetings with the pilot partners (22). Pilot partners then engaged with local communities, conducting workshops and focus groups (23), before constructing reports to be shared in the consortium on the results (24).

The third general assembly and series of design workshops (GA+DWS3) took place in the Netherlands in June 2017, and was a point whereby partners and work package leaders were able to update the entire consortium on the project's progress (25). In this case, the partners doing fieldwork have elaborated hints for design that include, for example, allowing people to express their needs in a way that could be collected, or foreseeing better chances for organised groups to promote themselves. As part of the plan for project self-evaluation, another selfevaluation focus group within the consortium was also carried out to trace members' feedback about project activities (26). A few relevant issues emerged including the difficulties the Croatian pilot has faced due to the general political climate in the country and troubles in conducting empirical research with participants, who are dispersed and difficult to intercept ${ }^{1}$. Similar to the first self-evaluation focus group, pilot partners especially the Dutch pilot - pointed to troubles in balancing time constraints prescribed by institutional deadlines and the longer time required by empirical activities with participants to be carried out.

Other outcomes from the GA+DWS3 included discussions about the process of designing and developing $\mathrm{R} 2$, which resulted in those involved in the technical processes constructing and sharing a work plan (27). At this point, one of the pilot partner organisations planned and organised additional workshops with participants, in order to supplement the information collected as part of previous exercises, providing additional reports (28). This serves to highlight workshops can exist as a tactical response to the strategies of the consortium, or as a planned strategy themselves.

These additional efforts contributed to a growing need for the consortium to reflect on the way in which we present and understand the design of commonfare.net. As such, we created a document that outlines the metaphors that we intend to convey, beginning at a very abstract level (e.g. commonfare.net as an ecology), before introducing more fine grained concepts that allow us to consider the actual interaction that would take

\footnotetext{
${ }^{1}$ It should be noted that the Croatian partner is a well known NGO in the country, with a lot of experience and diffused trust
} 


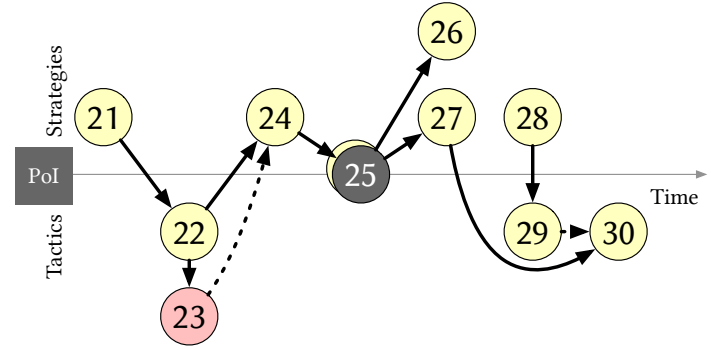

Figure 6. Strategies, Tactics of the Commonfare Consortium (yellow) and Participants (red); and Points of Infrastructure (grey) of the process from the R1 toward R2.

place, and from this, shape the visual forms that commonfare.net would take (29). The reports from the GA+DWS3, supported by this metaphor work, have informed a process of developing low fidelity mockups of R2 (30). These design activities have been elaborated, indeed, on the documents previously cited by BIN ITALIA [3] and Abertay University [1], and have both inductively abstracted from them in order to get a general guiding metaphor as a principle for design, and deductively derived functional requirements for commonfare.net.

\section{STRATEGIES AND TACTICS IN COMMONFARE}

The detailed biography of the Commonfare project, in its first year of activity, reveals some pivotal decisions and actions that affected both the short-term dynamics and the longer term evolution of the project and of the relations among the EC, the project consortium, and the participants. Through the BoA of Commonfare.net it has been possible to describe how the project and its main digital component have changed over time, while through the concepts of strategies and tactics it is possible to highlight whether decisions and actions - part of collaborative design practices - act on dimensions of space and power, or mobility and temporality.

When looking at what has been described from the point of view of our main research question - how can HCI scholars and designers understand the configuration of participation in a large scale infrastructuring project rooted in political economy - it is indeed possible to identify how the lens of strategies and tactics is helpful to understand the character of the different points of infrastructure in relation to commonfare.net as a technological artefact and Commonfare as a social aggregate including different actors, as the consortium members, the European Commission, and the participants. We identified six points of infrastructure - the approval of the project proposal by the European Commission; the signature of the Grant Agreement between the EC and the Consortium; the first design workshop; the second general assembly; the first release of commonfare.net; and the third general assembly) - and, in all of them it is possible to see how the design of commonfare.net, design intended as a process, a practice, and an object, has been constrained into redefined strategic boundaries. At the same time, the points of infrastructure delineate moments in which - in the context of the existing strategic boundaries for design - moments of tactical negotiations open up.
Examples of such a process of definition of strategic boundaries and practices of tactical negotiations are abundant in the BoA of Commonfare we sketched out: the proposal envisioned a strategic process as a tactical action in the boundaries of the call-for-proposals; the changing strategies of the European Commission in terms of research ethics have framed the possibilities available while transforming an approved proposal into a legally binding Grant Agreement; the Grant Agreement defined the boundaries of a design process that has been challenged and shaped by the tactical actions of the members of the Consortium and the participants; the General Assemblies and Design Workshops contributed to refine the boundaries for following design choices while in-between them tactical negotiations have been continuously taking place.

Therefore, any point of infrastructure we identified is a crossroad between the strategic, codified perspective, and the tactical actions available to open up the project to participation by the Consortium members and the participants in the field. One specific aspect, the use of language internally, and to communicate the project externally, is particularly helpful in deepening the understanding coming from the BoA of commonfare.net; and we will use it as an example of how strategies, tactics, and points of infrastructure intersect in a project as complex as Commonfare.

\section{Language}

Among the many strategic and tactical actions that have served to shape the current state of the project during its first year, the construction and use of language have been by all means the most significant issue. The decision and action to change the language of the project, starting from its very name, have in fact affected both the public and internal communication and, in a more traditional HCI sense, our understanding of the technical requirements based on the input of participants through empirical data collection and analysis. It is not by chance that the example used by de Certeau to illustrate the relationship between strategies and tactics pertains precisely to language, when he claims: "There is no lack of models, especially so far as language is concerned; language is indeed the privileged terrain on which to discern the formal rules proper to such practices" [9, Ch. 3]. Indeed, where a form of language works like a stable system - something that, in our case, corresponds to the language whereby the original proposal and grant agreements have been written - then it becomes an object to be manipulated by practitioners through situated uses and local arrangement. In our case, such manipulation took the shape of a new name for the project and the construction of an internal glossary, challenging the same strategic and institutional perspective visible in the official documents and language.

\section{Changing the Project Name}

The original choice of project name - 'PIE News' - can be seen as a tactical action made by the consortium in order to attend the EC language describing the so called "societal challenges" such as, in our case, Poverty, lack of Income and unEmployment. The choice of this name, therefore, clearly reflected the will to align the rhetoric of the consortium with one of the funding agencies. On the other hand, the collective 
decision, during the second General Assembly, to change the name of the project to Commonfare can be framed both as a tactical move that, in the long run, turns into a strategic choice. The tactical aspect lies in the will to act on feedback coming from pilot partners and workshop participants, which clearly rejected the acronym 'PIE' as well as some institutional definition describing them as "at risk of poverty and social exclusion". In the long term, the decision of changing the name of the project is also strategic as it serves as a stable discursive place to construct trustful relations with participants. However, there were different implications regarding the interaction with the EC, as the name was not able to be changed at the level of the project funding source. As such, Commonfare is now positioned as the public facing name (e.g. on Facebook), and the name that is used for the web presence, however there is a link to the project page (where updates about general progress and news, as well as the timeline and funding information are listed) that still contains references to 'PIE News'. This suggests that the construction of the collective identity of a project is rooted in the set of relations connecting the funding agency, the designers/consortium members, and the people we engaged with. Moreover, the first name was aligning the consortium with the funding agency and it was rejected by the people - in this case, the consortium has been acting tactically in the space of others, the funding agency and the engaged people. Anyway, these tactical actions have also opened up the space for strategic and theoretical thinking, as it allowed the strengthening of Commonfare, a concept that was theoretically present in the background of the consortium already when writing the proposal.

\section{Glossary}

The other outcome of the GA+DWS2 focus group related to confusion or conflict regarding a number of different terms and phrases that some members of the consortium used at various points. It became clear that the different baggage associated with different words combined with the varied and complex interdisciplinary background of consortium members that a discussion about language was necessary, and as part of this we would seek to create a glossary. There was discussion about perhaps distinguishing between internal project language and external language with the public, however, the agreed upon approach was to settle on a single language to avoid confusion, and to favor a deep alignment of the different members of the consortium. The decision to build a glossary is strategic not only for re-shaping the communication within the consortium, and to strengthen trust with the participants, but also as far as design is concerned. Indeed, the removal of some terms, and the effort to look for other rhetoric and cultural references, is already having an impact on the way the design team is approaching the design. For example, in the described metaphor documents we define the potential users of the platform not in a technical way (e.g. 'user', 'stakeholder'), but in a social way, reflecting their relation with commonfare and political economy in a wider way (e.g. 'commoner' is the name used for people using commonfare.net). In this case, the tactical response to the perspective of participants has become - for the Consortium - a strategic boundary influencing following choices.

\section{DISCUSSION AND CONCLUSION}

The analysis of long-term evolution and short-term dynamics of the project can be developed in terms of strategic boundaries and tactical negotiations that are entailed by the practices of the actors involved in the project to manage relations with each other, coping with tensions and concerns, and contributing to the process of infrastructuring.

When referring to our main research question - how can HCI scholars and designers understand the configuration of participation in a large scale infrastructuring project rooted in political economy? - we can return to literature that stresses the relevance of the installed base $[30,32,45]$ and the processes of configuration of participation [47]. Indeed, much of the work in this first year of the Commonfare project has served to continually iterate, through tactical negotiations, on our understanding of the installed base as a strategic boundary for action that follows.

For any given effort toward a point of infrastructure, the way in which all parties participate in the process of participatory design has involved tailoring of their configuration through tactical negotiations. Reflecting on our main research question, the first point to stress is that designers, in a case like Commonfare, are continuously engaging in tactical actions of appropriation of the installed base, be they technological artefacts or legally binding documents, in order to make space for deviations based on the empirical work done. Moreover, at any iteration, or point of infrastructure, what were previously tactical actions become more fixed, strategic elements, and the installed base on which further tactical actions are built.

This points towards a need for designers wishing to engage in ambitious infrastructuring projects to understand that the relationships will evolve over time, and that while there are strategic actions that can be taken in terms of planning research activities, that the activities are then interpreted and enacted by partner organisations in different contexts (both in terms of the organisation's expertise and background, as well as the particularities of any given country). As a result, the heterogeneous nature of the reports requires a higher level of communication and consideration, an overhead that is expected as the number of partners responsible for the project grows. Therefore, the concepts of strategies and tactics allow for a renewed understanding of the relations between the installed base and the configuration of participation, in which the way participation is configured allow for tactical negotiations on the installed base, being it technological artefacts or the understanding of the social context, and the results of such negotiations rebuild the installed base as renewed strategic boundaries for further design.

Returning to the key differences of Bødker et al. [4], the position of us as authors who also act within the consortium have given us a perspective on the relationships between the consortium and itself, the consortium and the EC, and the consortium and participants. This tension is one between the bottom-up ideals of Commonfare as a participatory design project that seeks to tactically respond to the changing circumstances, and the strategic space of the project as defined by the funding rules and expectations of the EC. Moreover, 
participatory design, in this case, is one of the ways through which the autonomy of social collaboration is fostered, as it entails possibilities for peoples' experiences and perspectives to influence the technology they will engage with, instead of being heteronomated by technologies built by more powerful actors. The problem of the configuration of participation in specific cases remains, and in our case has been addressed by adjusting the project language, and not only including inputs for the design of the materiality of digital technologies.

Reflecting on political economy and HCI, we have explicitly sought to address issues of political economy. In particular, the changes in the welfare state, where we have shown how the actions available to designers looking to support "real utopias" involve the intermixing relations among: institutional actors, the relevant social subjects, and a diverse set of organisations, including NGOs. These different relations constitute the forms of social collaboration through which autonomy from the dictates of heteronomation could take shape [16]. This is visible not only in the consortium composition but also, and more importantly, in the kind of bottom-up, autonomous, welfare practices that we have collected and that we are supporting.

Finally, we have shown how it is possible for HCI scholars and IT designers to engage in large scale participatory infrastructuring processes embedding a progressive agenda, and that implies a combination of strategic and tactical actions by the different social aggregates with which researchers build relations. The concepts of strategies and tactics, therefore, provide a useful lens through which to understand the types of actions that establish the relationships among the different actors involved in and around Commonfare, as well as to move the project towards its release goals. Our use of the installed base as the strategic iterative result of these actions, together with an understanding of the tactical changes in the configuration of participation, is a promising direction through which design projects can be described and further developed, also involving the detail of socio-technical choices connected to the strategic and tactical movements of the actors involved.

\section{ACKNOWLEDGMENTS}

This project has received funding from the European Union's Horizon 2020 research and innovation programme under grant agreement No. 687922.

\section{REFERENCES}

1. CN-FBK Abertay University, Dyne. 2017. Research Report 3.1. University of Trento, Basic Income Network Italy, Centre for Peace Studies, Stichting STAFF, CREATE-NET, Stichting Dyne.org, Abertay University, Madeira Interactive Technologies Institute (6 2017). http://pieproject. eu/wp-content/uploads/2017/07/PIE_ D3.1_FIN.pdf

2. Chiara Bassetti, Stefano De Paoli, Cristina Morini, Mariacristina Sciannamblo, and Maurizio Teli. 2017. Learning from financial outsiders. Rethinking communication to resist labelling (12th Annual International Ethnography Symposium).

3. BIN ITALIA. 2017. Research Report 2.1. University of Trento, Basic Income Network Italy, Centre for Peace
Studies, Museu da Crise (Daniela Paes Leão and Merel Willemsen), CREATE-NET, Stichting Dyne.org, Abertay University, Madeira Interactive Technologies Institute (3 2017). http://pieproject.eu/wp-content/uploads/2017/ 03/PIE_D2.1.pdf

4. Susanne Bødker, Henrik Korsgaard, Peter Lyle, and Joanna Saad-Sulonen. 2016b. Happenstance, Strategies and Tactics: Intrinsic Design in a Volunteer-based Community. In Proceedings of the 9th Nordic Conference on Human-Computer Interaction (NordiCHI '16). ACM, New York, NY, USA, Article 10, 10 pages. DOI : http://dx.doi .org/10.1145/2971485.2971564

5. Susanne Bødker, Henrik Korsgaard, and Joanna Saad-Sulonen. 2016a. 'A Farmer, a Place and at Least 20 Members': The Development of Artifact Ecologies in Volunteer-based Communities. In Proceedings of the 19th ACM Conference on Computer-Supported Cooperative Work \& Social Computing (CSCW'16). ACM, New York, NY, USA, 1142-1156. DOI : http://dx.doi.org/10.1145/2818048.2820029

6. Susanne Bødker, Peter Lyle, and Joanna Saad-Sulonen. 2017. Untangling the Mess of Technological Artifacts: Investigating Community Artifact Ecologies. In Proceedings of the 8th International Conference on Communities and Technologies (C\&T'17). ACM, New York, NY, USA, 246-255. DOI : http://dx.doi.org/10.1145/3083671.3083675

7. Francesco Botto and Maurizio Teli. 2017. PIE News. A public design project toward commonfare. The Journal of Community Informatics 13, 2 (2017). http:

//www.ci-journal.net/index.php/ciej/article/view/1383

8. Andrew Clement, Brenda McPhail, Karen Louise Smith, and Joseph Ferenbok. 2012. Probing, Mocking and Prototyping: Participatory Approaches to Identity Infrastructuring. In Proceedings of the 12th Participatory Design Conference: Research Papers - Volume 1 (PDC '12). ACM, New York, NY, USA, 21-30. DOI: http://dx.doi.org/10.1145/2347635.2347639

9. Michel de Certeau. 1984. The Practice of Everyday Life. University of California Press.

10. Carl DiSalvo, Andrew Clement, and Volkmar Pipek. 2012. Participatory design for, with, and by communities. International Handbook of Participatory Design. Simonsen, Jesper and Toni Robertson (Eds). Oxford: Routledge. (2012), 182-209.

11. Lynn Dombrowski, Adriana Alvarado Garcia, and Jessica Despard. 2017. Low-Wage Precarious Workers' Sociotechnical Practices Working Towards Addressing Wage Theft. In Proceedings of the 2017 CHI Conference on Human Factors in Computing Systems (CHI'17). ACM, New York, NY, USA, 4585-4598. DOI: http://dx.doi.org/10.1145/3025453.3025633

12. Paul Dourish. 2006. Re-space-ing Place: "Place" and "Space" Ten Years on. In Proceedings of the 2006 20th 
Anniversary Conference on Computer Supported Cooperative Work (CSCW'06). ACM, New York, NY, USA, 299-308. DOI :

http://dx.doi.org/10.1145/1180875.1180921

13. Hamid Ekbia and Bonnie Nardi. 2014. Heteromation and its (dis)contents: The invisible division of labor between humans and machines. First Monday 19, 6 (May 2014). http:

//firstmonday.org/ojs/index.php/fm/article/view/5331

14. Hamid Ekbia and Bonnie Nardi. 2015. The Political Economy of Computing: The Elephant in the HCI Room. interactions 22, 6 (2015), 46-49. DOI :

http://dx. doi.org/10.1145/2832117

15. Hamid Ekbia and Bonnie Nardi. 2016. Social Inequality and HCI: The View from Political Economy. In Proceedings of the 2016 CHI Conference on Human Factors in Computing Systems (CHI'16). ACM, New York, NY, USA, 4997-5002. DOI :

http://dx.doi .org/10.1145/2858036.2858343

16. Hamid R. Ekbia and Bonnie A. Nardi. 2017. Heteromation, and Other Stories of Computing and Capitalism. MIT Press. Google-Books-ID: WXPGDgAAQBAJ.

17. Eurostat. 2017. People at risk of poverty or social exclusion - Statistics Explained. (2017). http: //ec. europa.eu/eurostat/statistics-explained/index. php/People_at_risk_of_poverty_or_social_exclusion

18. Christian Fuchs. 2013. Digital Labour and Karl Marx. Routledge, New York, NY.

19. Andrea Fumagalli and Stefano Lucarelli. 2015. Finance, Austerity and Commonfare. Theory, Culture \& Society 32, 7-8 (2015), 51-65. DOI : http://dx.doi.org/10.1177/0263276415597771

20. David Hakken, Maurizio Teli, and Barbara Andrews. 2016. Beyond Capital: Values, Commons, Computing, and the Search for a Viable Future. Routledge, New York, NY.

21. David Harvey. 2007. A Brief History of Neoliberalism. OUP Oxford. Google-Books-ID: F5DZvEVt890C.

22. David Harvey. 2014. Seventeen Contradictions and the End of Capitalism. Oxford University Press, Oxford ; New York.

23. Liesbeth Huybrechts, Henric Benesch, and Jon Geib. 2017. Institutioning: Participatory Design, Co-Design and the public realm. CoDesign 13, 3 (2017), 148-159. http://www. tandfonline. com/doi/abs/10.1080/15710882 . 2017.1355006

24. Lilly C. Irani and M. Six Silberman. 2013. Turkopticon: Interrupting Worker Invisibility in Amazon Mechanical Turk. In Proceedings of the SIGCHI Conference on Human Factors in Computing Systems (CHI '13). ACM, New York, NY, USA, 611-620. DOI : http://dx.doi.org/10.1145/2470654.2470742

25. Margaret Jack, Jay Chen, and Steven J. Jackson. 2017. Infrastructure As Creative Action: Online Buying,
Selling, and Delivery in Phnom Penh. In Proceedings of the 2017 CHI Conference on Human Factors in Computing Systems (CHI '17). ACM, New York, NY, USA, 6511-6522. DOI : http://dx.doi .org/10.1145/3025453.3025889

26. Helena Karasti. 2014. Infrastructuring in Participatory Design. In Proceedings of the 13th Participatory Design Conference: Research Papers - Volume 1 (PDC'14). ACM, New York, NY, USA, 141-150. DOI: http://dx .doi .org/10.1145/2661435.2661450

27. Christopher A. Le Dantec. 2016. Designing Publics. MIT Press. Google-Books-ID: r6wDDQAAQBAJ.

28. Christopher A. Le Dantec and Carl DiSalvo. 2013. Infrastructuring and the formation of publics in participatory design. Social Studies of Science 43, 2 (April 2013), 241-264. DOI: http://dx. doi .org/10.1177/0306312712471581

29. Peter Lyle, Mariacristina Sciannamblo, and Maurizio Teli. 2017. Fostering Commonfare. Strategies and Tactics in a Collaborative Project. In Proceedings of the 29th Australian Conference on Computer-Human Interaction (OZCHI '17). ACM, New York, NY, USA, 443-447. DOI : http://dx. doi .org/10.1145/3152771.3156154

30. Sanna Marttila and Andrea Botero. 2017. Infrastructuring for Cultural Commons. Computer Supported Cooperative Work (CSCW) 26, 1 (01 Apr 2017), 97-133. DOI : http://dx.doi.org/10.1007/s10606-017-9273-1

31. Maria Menendez-Blanco, Antonella De Angeli, and Maurizio Teli. Biography of a Design Project through the Lens of a Facebook Page. (????), 1-26. DOI : http://dx. doi.org/10.1007/s10606-017-9270-4

32. Laura J Neumann and Susan Leigh Star. 1996. Making infrastructure: The dream of a common language. In PDC. 231-240.

33. Elinor Ostrom. 1990. Governing the commons: The evolution of institutions for collective action. Cambridge university press.

34. Elena Parmiggiani. 2017. This Is Not a Fish: On the Scale and Politics of Infrastructure Design Studies. Computer Supported Cooperative Work (CSCW) 26, 1 (01 Apr 2017), 205-243. DOI :

http://dx.doi.org/10.1007/s10606-017-9266-0

35. Thomas Piketty. 2014. Capital in the Twenty-First Century. Harvard University Press.

36. Volkmar Pipek and Volker Wulf. 2009. Infrastructuring: Toward an integrated perspective on the design and use of information technology. Journal of the Association for Information Systems 10, 5 (2009), 447.

37. Neil Pollock and Robin Williams. 2010. e-Infrastructures: How Do We Know and Understand Them? Strategic Ethnography and the Biography of Artefacts. Computer Supported Cooperative Work (CSCW) 19, 6 (01 Dec 2010), 521-556. DOI :

http://dx.doi.org/10.1007/s10606-010-9129-4 
38. Trebor Scholz. 2016. Uberworked and Underpaid: How Workers Are Disrupting the Digital Economy. John Wiley \& Sons. Google-Books-ID: LiDNDQAAQBAJ.

39. Mariacristina Sciannamblo and Maurizio Teli. 2017. Undoing the Ontology of the Poor: A Participatory Design Project. (2017).

http://www . 4sonline.org/blog/post/undoing_the_ ontology_of_the_poor_a_participatory_design_project

40. F. Sestini. 2012. Collective Awareness Platforms: Engines for Sustainability and Ethics. IEEE Technology and Society Magazine 31, 4 (2012), 54-62. DOI: http://dx.doi.org/10.1109/MTS.2012.2225457

41. Stephen Snow, Dhaval Vyas, and Margot Brereton. 2017. Sharing, Saving, and Living Well on Less: Supporting Social Connectedness to Mitigate Financial Hardship. International Journal of Human-Computer Interaction 33, 5 (2017), 345-356. DOI :

http://dx.doi.org/10.1080/10447318.2016.1243846

42. Stephen Snow, Dhaval Vyas, Peter Lyle, Miranda Mallett, and Margot Brereton. 2016. Building Connections: Technology Design for Living on a Low Income. In Proceedings of the 14th Participatory Design Conference: Short Papers, Interactive Exhibitions, Workshops Volume 2 (PDC '16). ACM, New York, NY, USA, 1-4. DOI:http://dx.doi.org/10.1145/2948076.2948091

43. Nick Srnicek. 2016. Platform Capitalism. John Wiley \& Sons. Google-Books-ID: 3yrJDQAAQBAJ.
44. Susan Leigh Star and Karen Ruhleder. 1996a. Steps Toward an Ecology of Infrastructure: Design and Access for Large Information Spaces. Information Systems Research 7, 1 (1996), 111-134. DOI : http://dx.doi.org/10.1287/isre.7.1.111

45. Susan Leigh Star and Karen Ruhleder. 1996b. Steps Toward an Ecology of Infrastructure: Design and Access for Large Information Spaces. Information Systems Research 7, 1 (1996), 111-134. DOI: http://dx.doi.org/10.1287/isre.7.1.111

46. Maurizio Teli, Silvia Bordin, MarÃ MenÃl'ndez Blanco, Giusi Orabona, and Antonella De Angeli. 2015. Public design of digital commons in urban places: A case study. International Journal of Human-Computer Studies 81 (2015), 17-30. DOI: http://dx.doi.org/10.1016/j.ijhcs.2015.02.003

47. John Vines, Rachel Clarke, Peter Wright, John McCarthy, and Patrick Olivier. 2013. Configuring Participation: On How We Involve People in Design. In Proceedings of the SIGCHI Conference on Human Factors in Computing Systems (CHI'13). ACM, New York, NY, USA, 429-438. DOI:http://dx.doi.org/10.1145/2470654.2470716

48. Erik Olin Wright. 2013. Transforming Capitalism through Real Utopias. American Sociological Review 78, 1 (Feb. 2013), 1-25. DOI :

http://dx.doi .org/10.1177/0003122412468882 